\title{
Surgical treatment of skin lesions in lupus erythematosus
}

\author{
Edward Lewandowicz, Tomasz Zieliński, Aleksandra Iljin, Marta Fijałkowska, Anna Kasielska-Trojan, \\ Bogusław Antoszewski
}

Plastic, Reconstructive and Aesthetic Surgery Clinic, Medical University of Lodz, Lodz, Poland Head of the Clinic: Prof. Bogusław Antoszewski MD, PhD

Postep Derm Alergol 2014; XXXI, 6: 405-409

DOI: 10.5114/pdia.2014.40931

\begin{abstract}
Lipodystrophies are a wide group of diseases with various etiology, mainly genetic, metabolic or autoimmune. The treatment of these diseases is chronic and not always effective. Major concerns for patients with lipodystrophies are also esthetic defects, especially deformities in the face, neck and upper limbs. There are many surgical methods that can be used to improve patient's appearance like fillers, autologous fat transfer and skin flaps. The aim of this paper is to present and discuss surgical techniques used for correction of lipoatrophy and other skin lesions present in lupus erythematosus. In the first presented patient, lipodermal grafts were performed in two stages (first - to both zygomatic areas, the second - to both nasolabial folds). Moreover, the patient was qualified for arm scar plasty. Deepithelialized skin in the affected area was covered with advanced local skin flaps. In the second patient, an extensive scarring lesion on the scalp was excised and the defect was closed with an expanded scalp flap. Patients with lipodystrophies may require aesthetic surgical procedures to improve their appearance. In patients with lupus erythematosus, autologous fat graft in the face area seems to be a safe and effective method of refilling the volume of atrophic tissues. On the basis of our experience, it is worth emphasizing that the process of fat graft resorption is typical. In patients with scalp scars, an effective method of their removal and hairline restoring is usage of the tissue expander.
\end{abstract}

Key words: lupus erythematosus, lipodermal graft, tissue expander.

\section{Introduction}

Lipodystrophy disorders are a group of heterogeneous conditions connected with defective metabolism and progressive loss of fat that affects the subcutaneous tissue of the face, upper limbs, thoracic region, occasionally extending to the groins or thighs, and rarely visceral compartment. Multiple genetic forms are often associated with other metabolic and systemic anomalies, and result in a gradually progressive lipoatrophy accompanied by redistribution of the fat especially in the upper body. Acquired types can be related to various autoimmune disorders, e.g. lupus erythematosus [1, 2]. As many as $30 \%$ of patients afflicted with lupus present dermatological symptoms on the face like malar rash, thick, red scaly patches on the skin, and less frequent alopecia, mouth, nasal, urinary tract and vaginal ulcers, and other lesions of the skin [3, 4]. Scarring and lipoatrophy exposed on the face can be a psychological problem. The cheeks, zygomatic areas and nasolabial folds are the most common sites treated surgically where a limited functional restoration and good aesthetic results can be obtained. Improvement in the case of small facial contour deformities can be achieved with autogenic fat grafts or lipodermal grafts. Fat grafts transferred by lipoinjection are subject to resorption processes, similarly to surgical grafts. The limitation of this popular technique is the volume of the injected fat, as excessive fat transfer may jeopardize revascularization. However, the procedure can be repeated multiple times and donor site morbidity is minimal [5]. Grafts supplementation with adipose-derived stem/stromal cells (CAL technique) may prove superior to the facial recontouring technique employed in patients with lupus profundus [6].

In some cases, dermal fillers like hyaluronic acid may be helpful in scar depression correction [7, 8]. Major areas of the resected necrotic skin together with the soft tissue defect may require coverage with either local or microvascular free tissue transfer. Different methods of local plasty can be indicated depending on the size and location of the lesion. Scalp defects can also be reconstructed with the use of expanders or the technique called "Nordström Suture" [9]. Unlike fat grafting, the free flaps transferred for facial contour reconstruction provide large

Address for correspondence: Prof. Bogusław Antoszewski MD, PhD, Plastic, Reconstructive and Aesthetic Surgery Clinic, University Clinical Hospital No. 1, 22 Kopcinskiego St, 90-153 Lodz, phone: +48 426776 742, e-mail: b.antoszewski@wp.pl Received: 17.07.2013, accepted: 18.09.2013. 
volumes of reliable tissue. Disadvantages of these techniques include longer operative times and hospital stays, donor site scarring and morbidity. Deposition of immunoglobulins along the vascular basement membranes and often concomitant hypercoagulability in patients afflicted with collagen vascular diseases increase their risk of thrombosis. However, data from some authors deny any significant increase in microvascular flap complications in this population of patients and therefore they should not be excluded from free flap reconstruction [10, 11]. Also, the results of microsurgical correction of bilateral soft-tissue facial contour deformities show that it seems to be superior to unilateral cases [11]. The most commonly used microsurgical flaps include: anterolateral thigh and radial forearm flaps, superficial inferior epigastric flaps or inframammary extended circumflex scapular flaps for head and neck reconstruction [10-12].

The aim of this paper is to present and discuss surgical techniques used for correction of lipoatrophy and other skin lesions present in lupus erythematosus, on the basis of our own experiences.

\section{Case reports}

\section{Patient 1}

A woman aged 48 presented to the Plastic Surgery Out-Patient Clinic with severe atrophic lesions of fatty tissue in the cheeks, frontal area and left arm. Lipoatrophy and scarring skin lesions (lipodystrophy) were present in the zygomatic area, nasolabial folds, forehead and fronto-parietal scalp. The lesions were multifocal and well circumscribed

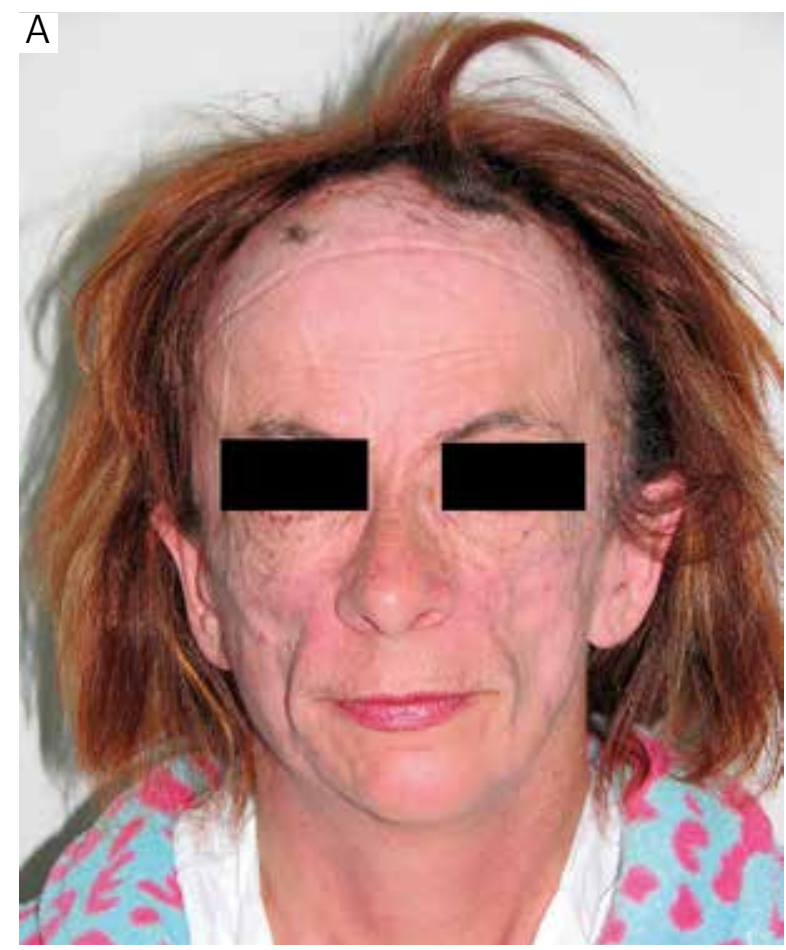

from the adjacent tissues (Figures 1 A, B). Medical history revealed that lipoatrophy has been proceeding for about 30 years. The patient was diagnosed with lupus erythematosus profundus (lupus panniculitis - LEP). Pharmacological treatment did not cause reduction of skin lesions and improvement of fatty tissue distribution. After finishing therapy, the patient was qualified for surgical corrections in the Plastic, Reconstructive and Aesthetic Surgery Clinic. At first, lipodermal graft from the gluteal fold was transferred to both zygomatic areas. Due to the basic illness and increased risk of graft atrophy, the patient was followed-up in the Out-Patient Clinic for 12 months. After a year, we observed a partial graft resorption, however the long-term outcome was very good (Figure $2 \mathrm{~A}$ ). Then, the patient was planned for the next stage of surgical treatment and lipodermal graft from the gluteal fold was transferred to fill deficits in both nasolabial folds. After 3 months from the previous procedure, the left arm plasty was performed - deepithelialized skin in the affected area was covered with advanced local skin flaps. Currently, 2 years after the first surgical procedure, the aesthetic result in the aspects of face and arm contour is satisfactory (Figures $2 \mathrm{~B}, \mathrm{C}$ ).

\section{Patient 2}

A patient aged 59 presented to the Plastic Surgery Out-Patient Clinic with an extensive scarring lesion on the scalp. Medical history revealed that about 20 years before she was diagnosed with systemic lupus erythematosus (SLE) and treated pharmacologically. At the time of consultation, the autoimmune process was in remission and the observed scalp scar was a result of SLE. The size

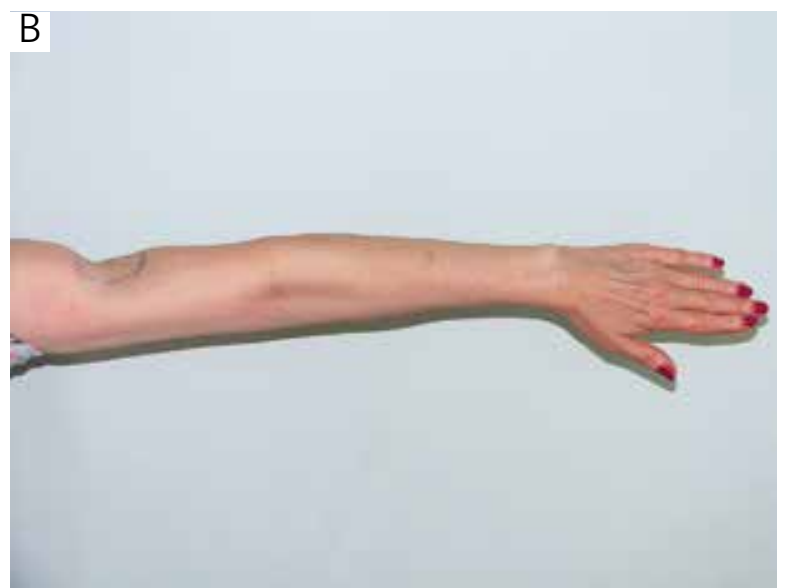

Figure 1. Patient aged 48. A - Face lesions. B - Lesions on the arm 

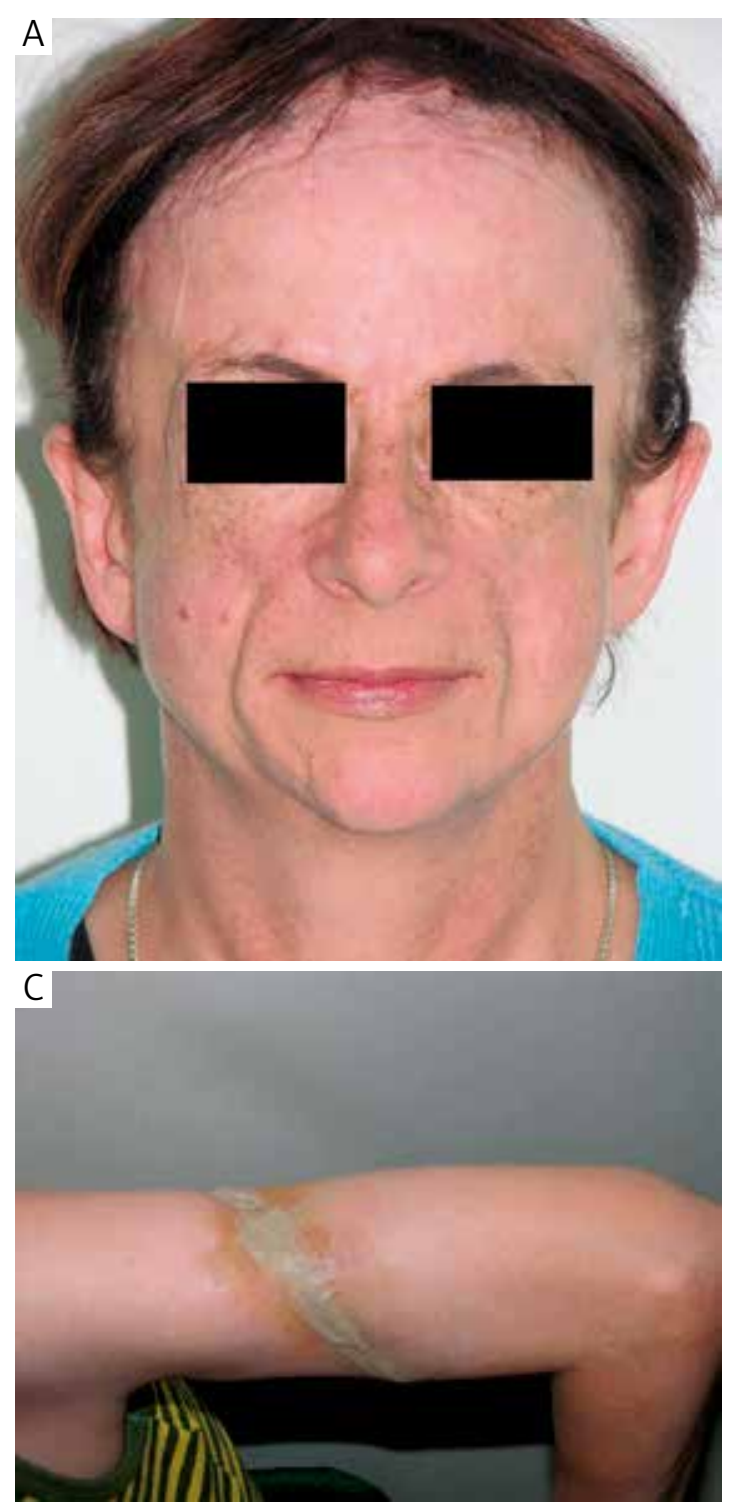

of the lesion was $7 \mathrm{~cm} \times 6 \mathrm{~cm}$ and it was located in the parietal area, on the left to the midline (Figure 3 ). The patient was qualified for treatment in the Clinic. At first, Eurosilicone $250 \mathrm{cc}$ tissue expander was implanted under the unaffected scalp. During the next 2 months, the expander was gradually filled to the final volume (Figure 4 A). Then, it was removed and the scar in the parietal scalp was excised, and the defect was closed with an expanded scalp flap. The healing process was uncomplicated and the esthetic result assessed 12 months after the last procedure is very good (Figure $4 \mathrm{~B}$ ).

\section{Discussion}

Lipodystrophies are a wide group of diseases with various etiology, mainly genetic, metabolic or autoimmune $[2,13]$. The treatment of this disease is chronic

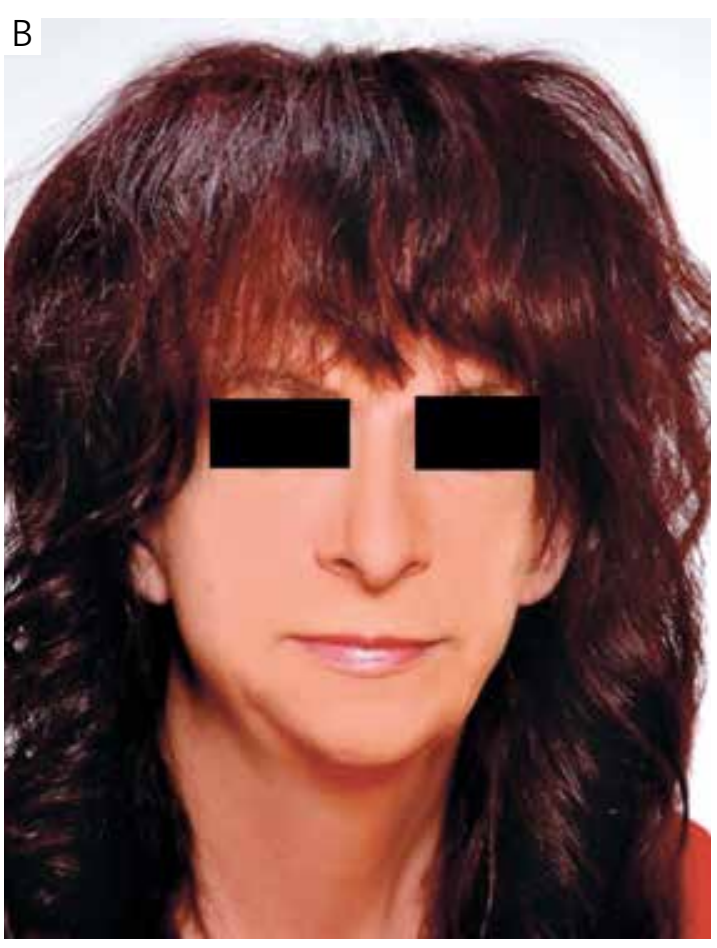

Figure 2. A - Status post lipodermal grafts transfer to both zygomatic areas. B - Status post lipodermal grafts transfer to both zygomatic areas and nasolabial folds. C - Status post arm plasty

and not always effective. Proper diagnosis and adequate drug administration are of fundamental importance. Major concerns for patients with lipodystrophies are also aesthetic defects [13]. That is why for such patients, apart from general treatment, possibilities to eliminate the cosmetic malformations are also important. Correction procedures are performed mainly on the exposed body parts - face, neck and upper limbs.

There are many surgical methods to improve the patient's appearance and the choice of technique depends on the severity of the process and the preference of the surgical center. One of the possibilities is to correct face or neck contours using the autologous fat [5]. Pinski and Roenigk showed the results of surgical treatment in a group of 43 patients. All patients underwent autologous fat transplantation and indications included mainly lupus erythematosus. Authors concluded that autologous 


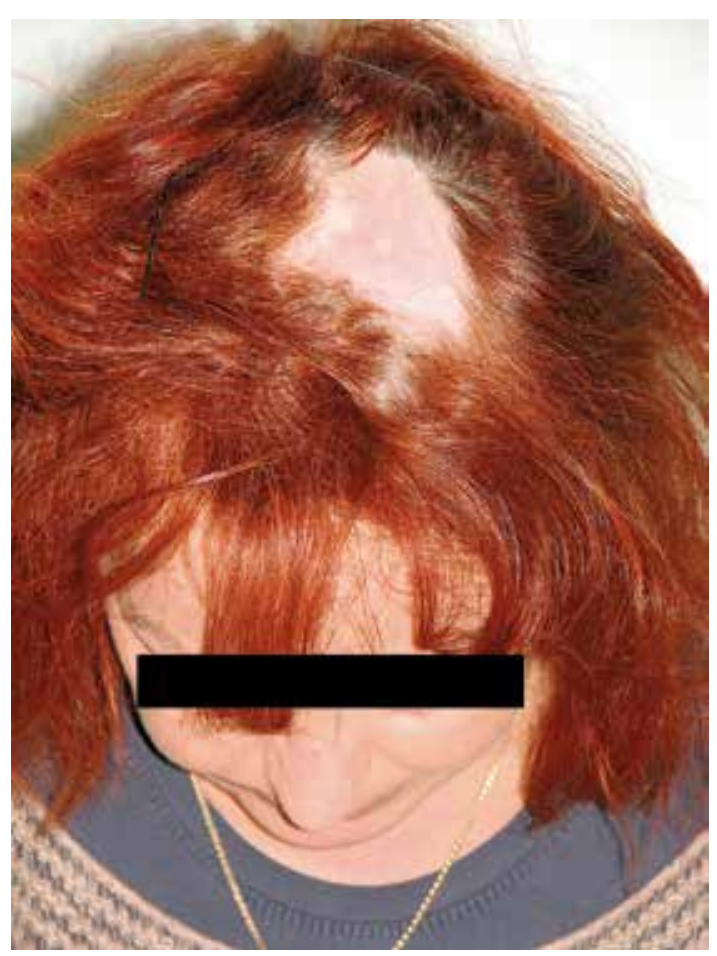

Figure 3. Patient aged 59: scalp lesion

fat transplantation is a safe and effective procedure, with long follow-up observations (mean 26 months) [14]. Yoon et al. suggested that the autologous fat transfer is a good choice to correct face atrophic lesions in patients with lupus erythematosus. Unquestionable advantages of this
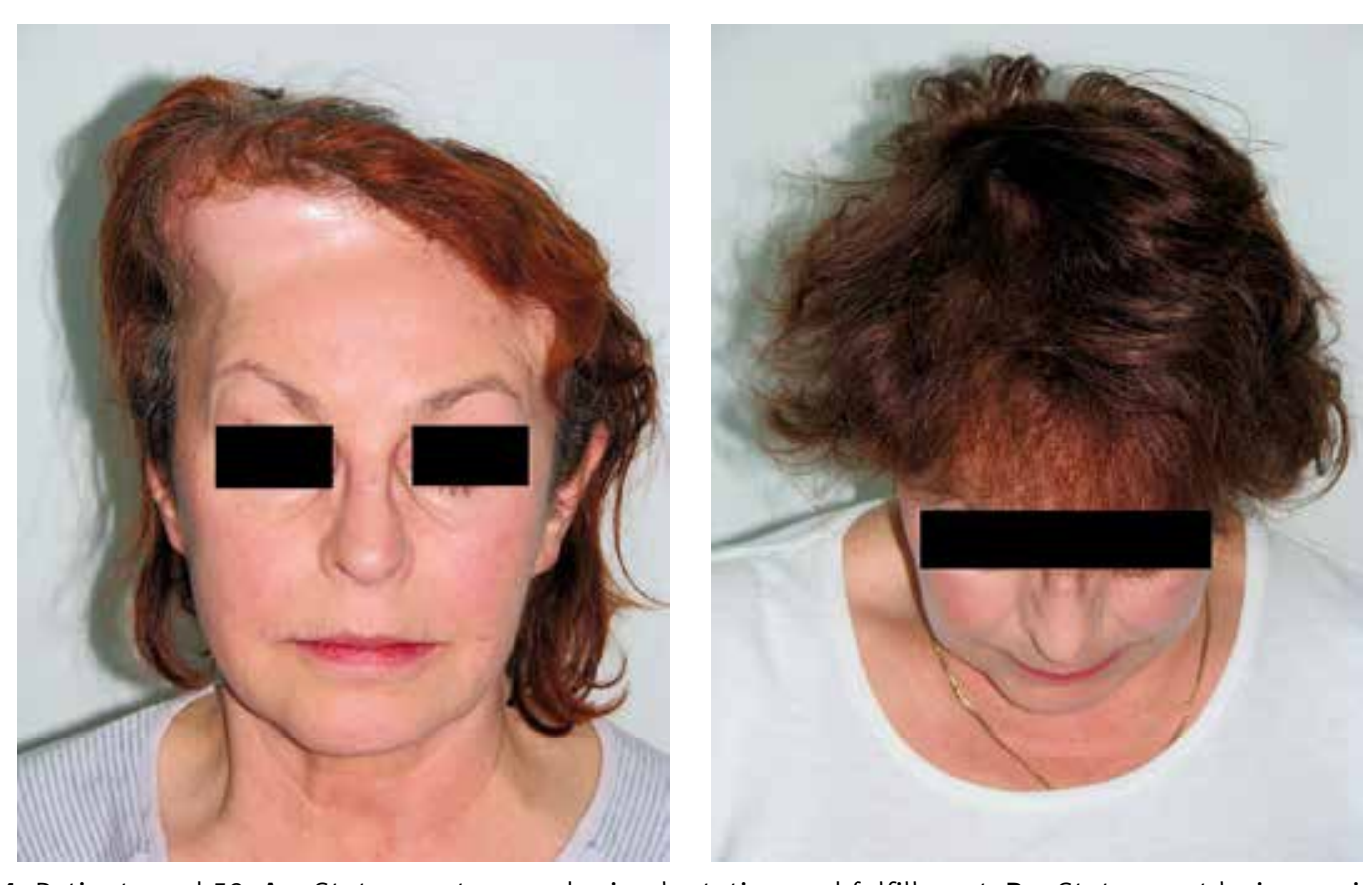

Figure 4. Patient aged 59. A - Status post expander implantation and fulfillment. B - Status post lesion excision and defect closure with an expanded scalp flap method are that the material used is patients' own tissue (biocompatible), it has no allergic reaction and is easy to harvest [15]. A similar treatment path was introduced in the first described patient. Fat graft was performed twice, in the first stage to cheeks in the zygomatic area, while during the second stage to the area of nasolabial folds. Currently, 2 years after the treatment was introduced, a good long-term aesthetic result is observed, and fat resorption is typical.

The usage of tissue expanders on the scalp makes it possible to excise the scalp scar, followed by defect closure with expanded skin and hairline restoration. Such surgical procedures are introduced in patients after burns or with alopecia $[16,17]$. Tissue expander was implanted in the second described patient, in whom the scalp scar developed in the course of lupus erythematosus. The lesion was extensive and caused a cosmetic defect. The treatment resulted in good aesthetic effects.

\section{Conclusions}

Patients with lipodystrophies, independently of the disease cause, may require aesthetic surgical procedures to improve their appearance. The plan of surgical treatment should be individual and depends on the localization and extension of lipoatrophy. In patients with lupus erythematosus autologous fat graft in the face area seems to be a safe and effective method of refilling the volume of atrophic tissues. It is worth emphasizing that the process of fat graft resorption is typical and placing autologous fat in the atrophic area does not accelerate 
the fat resorption. The state of tissue hypercorrection allows for achieving more lasting and satisfactory surgical effects. In patients with scalp scars, the effective method of their removal and hairline restoring is the usage of the tissue expander.

\section{References}

1. Garg A. Lipodystrophies. Am J Med 2000; 108: 143-52.

2. Garg A. Acquired and inherited lipodystrophies. N Engl J Med 2004; 350: 1220-34.

3. James W, Berger T, Elston D. Andrews' diseases of the skin: clinical dermatology. 10th ed. Saunders 2005.

4. Rahman A, Isenberg DA. Systemic lupus erythematosus. N Engl J Med 2008; 358: 929-39.

5. Cortese A, Savastano G, Felicetta L. Free fat transplantation for facial tissue augmentation. J Oral Maxillofac Surg 2000; 58: 164-9.

6. Yoshimura K, Sato K, Aoi N, et al. Cell-assisted lipotransfer for facial lipoatrophy: efficacy of clinical use of adipose-derived stem cells. Dermatol Surg 2008; 34: 1178-85.

7. Cooper J, Lee B. Treatment of facial scarring: lasers, filler, and nonoperative techniques. Facial Plast Surg 2009; 25: 311-5.

8. Lemperle G, Rullan PP, Gauthier-Hazan N. Avoiding and treating dermal filler complications. Plast Reconstr Surg 2006; 118 (3 Suppl.): 92S-107S.

9. Nordström REA. The "Nordström suture" to enhance serial scalp reductions and other serial excisions as well as to treat and prevent scar widening. Semin Plast Surg 2005; 19: 137-42.

10. Raurell A, Austin OM, Ramakrishnan V. Free tissue transfer in patients with systemic lupus erythematosus. Br J Plast Surg 2000; 53: 77-9.

11. Longaker MT, Flynn A, Siebert JW. Microsurgical correction of bilateral facial contour deformities. Plast Reconstr Surg 1996; 98: 951-7.

12. Wang TY, Serletti JM, Kolasinski S, et al. A review of 32 free flaps in patients with collagen vascular disorders. Plast Reconstr Surg 2012; 129: 421e-7e.

13. Oświęcimska J, Ziora K, Dyduch A. Acquired and congenital lipodystrophy [Polish]. Endokrynologia, Otyłość i Zaburzenia Przemiany Materii 2006; 2: 22-9.

14. Pinski KS, Roenigk HH Jr. Autologous fat transplantation. Long-term follow-up. J Dermatol Surg Oncol 1992; 18: 179-84.

15. Yoon J, Kim HM, Kim TH, et al. Autologous fat transfer in a patient with lupus erythematosus profundus. Case Rep Dermatol 2012; 4: 207-10.

16. Motamed S, Niazi F, Atarian S, Motamed A. Post-burn head and neck reconstruction using tissue expanders. Burns 2008; 34: 878-84.

17. Hassan AS. Surgical treatment of secondary cicatricial alopecia of scalp and eyebrow. Indian J Plast Surg 2009; 42: 63-7. 